\title{
INTRAVASCULAR OSTEOCLASTS
}

\author{
R. A. Sladden, Northampton, England
}

Formerly of the Division of Laboratories, United Oxford Hospitals and the Nuffield Orthopaedic Centre

During the routine diagnostic examination of histological sections from a tumour of the radius (Case 1), it was observed that numerous small blood vessels contained osteoclastic giant cells like those that were present in the tumour. The blood vessels involved were situated in the connective tissues outside the periphery of the tumour (Figs. 1 to 4). The tumour was an osteoclastoma of a well differentiated type, and was classified according to the criteria suggested by Jaffe, Lichtenstein and Portis (1940) as a Grade 1 tumour.

The apparently benign nature of this tumour made it unlikely that the presence of these intravascular giant cells would adversely affect the prognosis, but at the same time it was by no means certain whether or not such a finding had previously been reported.

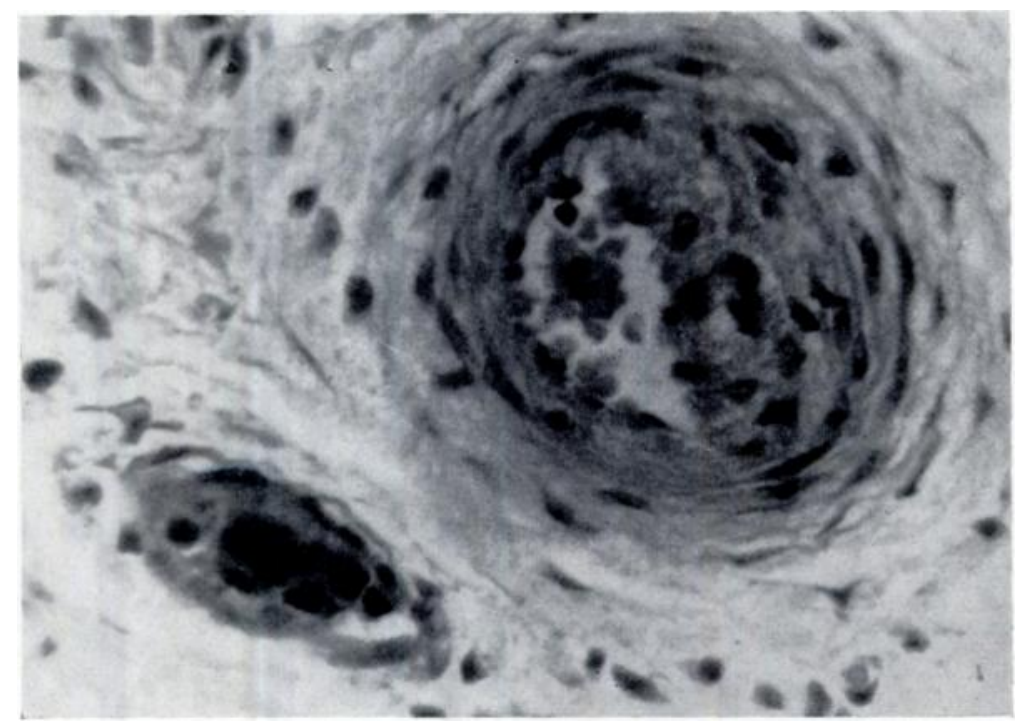

FIG. 1

Case 1-Small blood vessels outside the tumour periphery, showing an intravascular osteoclast and a half-obliterated vessel. (H. and E., $\times 425$.)

Examination of the literature showed that, although there were some references to osteoclastic giant cells lying in "blood spaces" within osteoclastomas, there was apparently no clear description of intravascular osteoclasts in these tumours. The nearest approach to such a description was found in an account of the giant-cell tumour of bone by Harvey, Dawson and Innes (1940). These authors stated: "It is common for the multinucleated giant cells to project into apparent capillary blood spaces (Figs. 2 and 3) or even to be free in their lumen." There is, however, a qualification of this statement in the captions to these figures. Figure 3 is described thus: "Giant cell tumour of bone. Head of humerus. Same case as in Figures 1 and 2 showing multinucleated giant cells projecting into apparent spaces usually regarded as vascular, but which we interpret as probably structureless." The " spaces " referred to, and similar descriptions of "blood spaces" by other writers, may be interpreted as expressions of the loose texture and haemorrhagic nature of the stroma of osteoclastomas. 
Since it seemed that no adequate description of intravascular osteoclasts had been made, it was decided to re-examine material from other cases of osteoclastoma for further evidence of the phenomenon, but at the same time it was clear that the presence of osteoclasts within blood vessels could be regarded as established only if the walls of the vessels concerned were

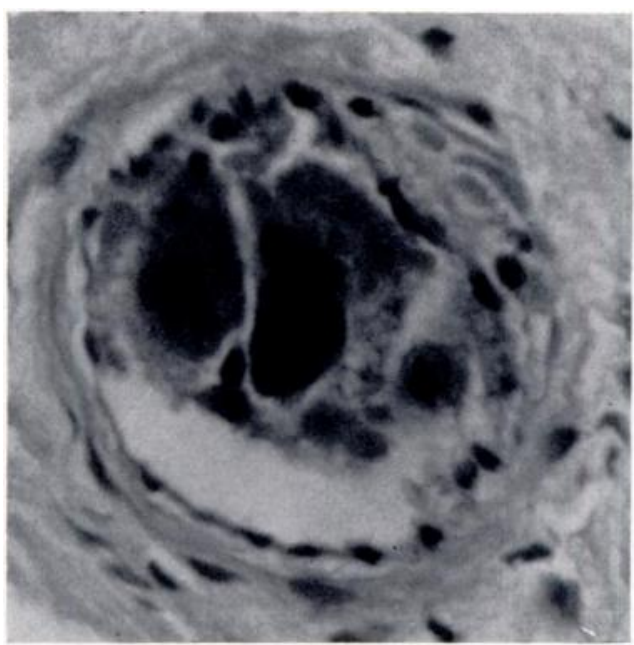

Fig. 2

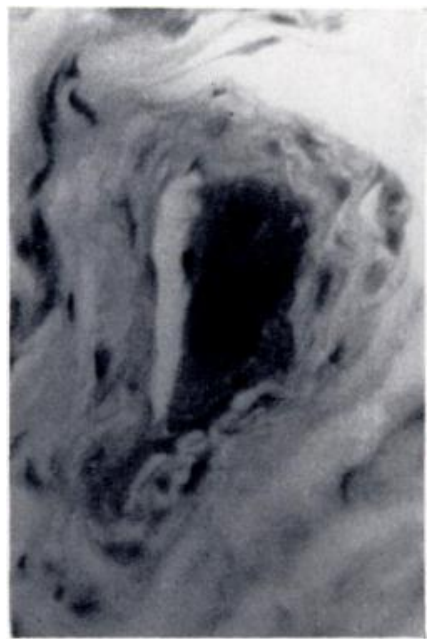

FIG. 3

Case 1. Figure 2-A blood vessel containing two osteoclasts. (H. and E., 550.) Figure 3-A blood vessel containing a single osteoclast. (H. and E., 350 .)

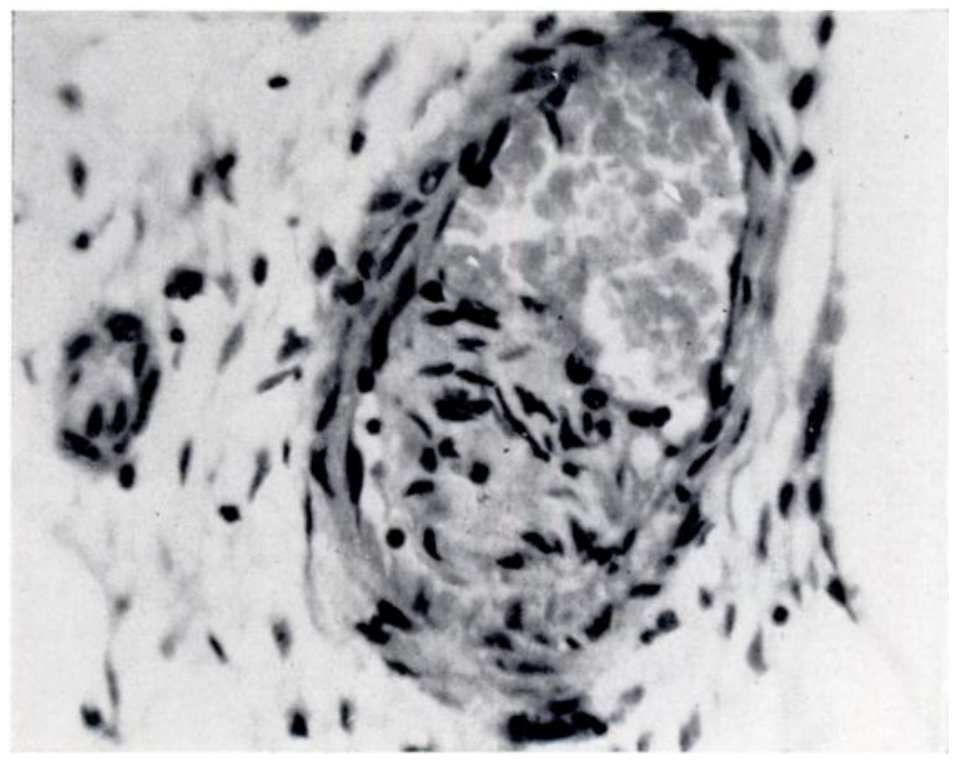

Fig. 4

Case 1-A small blood vessel lying outside the periphery of the tumour is half obliterated by the remnant of what was probably an osteoclast. There is replacement of the nuclei by nuclei of fibrocytic type. (H. and E., $\times 375$.)

definitely identified, and if the possibility of artefactual "knife-emboli" could be excluded beyond reasonable doubt.

The examination of material from other cases of osteoclastoma was undertaken in order to investigate the following points: 1) The frequency with which intravascular osteoclasts 
TABLE I

Detalls of the Eleven Cases Studied

\begin{tabular}{|c|c|c|c|c|c|c|c|}
\hline Case & Sex & Age & Site & Grade & Treatment & Follow-up & Intravascular osteoclasts \\
\hline 1 & $\mathbf{M}$ & 36 & Distal radius & 1 & $\begin{array}{l}\text { Excision and } \\
\text { local radiotherapy }\end{array}$ & $\begin{array}{l}\text { Well after } \\
13 \text { months }\end{array}$ & $\begin{array}{c}\text { Numerous } \\
\text { intravascular osteoclasts }\end{array}$ \\
\hline 2 & $\mathbf{M}$ & 13 & Sacrum & 1 & $\begin{array}{l}\text { Curettage and } \\
\text { radiotherapy }\end{array}$ & $\begin{array}{l}\text { Well after } \\
4 \text { years }\end{array}$ & $\begin{array}{l}\text { No intravascular } \\
\text { osteoclasts found }\end{array}$ \\
\hline 3 & $\mathbf{F}$ & 20 & Proximal tibia & 1 & $\begin{array}{l}\text { Mid-thigh } \\
\text { amputation }\end{array}$ & $\begin{array}{l}\text { Well after } \\
13 \text { years }\end{array}$ & $\begin{array}{l}\text { One or more } \\
\text { intravascular osteoclasts }\end{array}$ \\
\hline 4 & $\mathbf{M}$ & 24 & Sacrum & 1 & $\begin{array}{l}\text { Curettage and } \\
\text { radiotherapy }\end{array}$ & $\begin{array}{l}\text { Well } 1 \text { year } \\
\text { after operation }\end{array}$ & $\begin{array}{l}\text { No intravascular } \\
\text { osteoclasts found }\end{array}$ \\
\hline 5 & $\mathbf{F}$ & 13 & Proximal fibula & 1 & Excision & $\begin{array}{l}\text { Well after } \\
20 \text { months }\end{array}$ & $\begin{array}{l}\text { Protrusion of osteoclasts } \\
\text { into blood vessels }\end{array}$ \\
\hline 6 & $\mathbf{F}$ & 16 & Distal femur & 1 & $\begin{array}{l}\text { Mid-thigh } \\
\text { amputation }\end{array}$ & $\begin{array}{l}\text { Well after } \\
12 \text { years }\end{array}$ & $\begin{array}{l}\text { Protrusion of osteoclasts } \\
\text { into blood vessels }\end{array}$ \\
\hline 7 & $\mathbf{M}$ & 39 & Pelvis & 2 & $\begin{array}{l}\text { Curettage and } \\
\text { radiotherapy }\end{array}$ & $\begin{array}{l}\text { Well after } \\
31 \text { years }\end{array}$ & $\begin{array}{l}\text { No intravascular } \\
\text { osteoclasts found }\end{array}$ \\
\hline 8 & $\mathbf{F}$ & 27 & Proximal tibia & 2 & $\begin{array}{l}\text { Mid-thigh } \\
\text { amputation }\end{array}$ & $\begin{array}{l}\text { Well after } \\
12 \text { years }\end{array}$ & $\begin{array}{c}\text { One or more } \\
\text { intravascular osteoclasts }\end{array}$ \\
\hline 9 & $\mathbf{M}$ & 39 & Lumbar spine & 2 & $\begin{array}{l}\text { Curettage and } \\
\text { radiotherapy }\end{array}$ & $\begin{array}{l}\text { Well after } \\
5 \text { months }\end{array}$ & $\begin{array}{c}\text { One or more } \\
\text { intravascular osteoclasts }\end{array}$ \\
\hline 10 & $\mathbf{M}$ & 75 & Calcaneum & 3 & Amputation & $\begin{array}{c}\text { Dead } 2 \text { years later. } \\
\text { No known } \\
\text { metastases }\end{array}$ & $\begin{array}{l}\text { No intravascular } \\
\text { osteoclasts found }\end{array}$ \\
\hline 11 & $\mathrm{~F}$ & 16 & Distal femur & 3 & Amputation & Recent case & $\begin{array}{c}\text { One or more } \\
\text { intravascular osteoclasts }\end{array}$ \\
\hline
\end{tabular}

could be found in cases of osteoclastoma; 2 ) the possible modes of entry of the osteoclasts into the blood stream; 3) the fate of these intravascular giant cells; and 4) the significance of the findings in relation to histological and clinical criteria of malignancy.

\section{MATERIAL}

Eleven cases of osteoclastoma (giant-cell tumour of bone) were found in the records of the Radcliffe Infirmary, Oxford, and of the Nuffield Orthopaedic Centre (formerly the Wingfield-Morris Orthopaedic Hospital), Oxford, for the period between 1940 and 1955. This figure includes the case which has already been mentioned. Some other cases in the records were rejected because histological material from them was not available.

The sections examined were the routine ones which had been prepared for histological diagnosis. Reticulin preparations were also made when they were not already available. On the whole, however, the observations described below might have been made at any routine histological examination.

The tumours were also graded histologically according to the criteria of Jaffe et al. (1940).

An attempt was made to follow the progress of the various patients in whom these tumours had arisen, but in one case (Case 4) it was not possible to obtain recent information about the patient's state of health.

The details of these eleven cases are summarised in Table I. The cases are grouped according to the histological grading of the tumours, but are not otherwise arranged in any special order. 


\section{OBSERVATIONS}

In five cases out of eleven, intravascular giant cells of osteoclastic type were found. In two of these five the vascular involvement was outside the periphery of the tumours (Cases 1 and 3: Figs. 1 to 5). In Case 1, as has been stated already, many vessels were affected. In the remaining four cases one, or at most two, vessels were found to be involved. The amount of tissue available for examination varied considerably from one case to another. Two of these five tumours were placed in Grade 1, two in Grade 2, and one in Grade 3.

Two further cases in Grade 1 (Cases 5 and 6) showed protrusion of osteoclasts into the blood vessels (Fig. 8), but in these cases osteoclasts were not found lying free within the blood vessels.

In the remaining four cases it was not possible to find intravascular osteoclasts. In two of these cases the histological material was fragmentary, having been obtained by drill biopsy or curettage.

It was observed that there was occasionally some inflammatory reaction around blood vessels which contained osteoclasts, when these vessels were outside the tumour periphery. There was sometimes a slightly more widespread inflammatory reaction (Fig. 5).

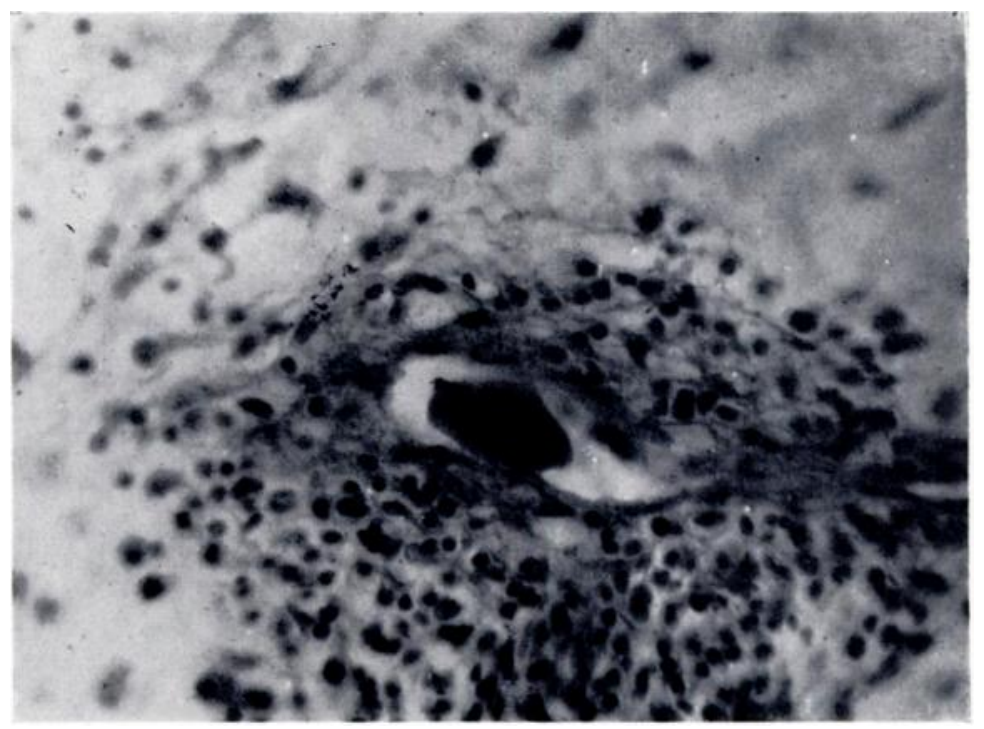

Fig. 5

Case 3-An osteoclast lying in the lumen of a small blood vessel. The vessel is lying outside the periphery of the tumour and there is a marked perivascular inflammatory reaction. ( $H$. and $E ., \times 340$.)

Some of the blood vessels in Case 1 showed apparent impaction of osteoclasts, with subsequent degeneration of the giant cells or their replacement by fibrosis and incorporation into the vessel wall (Figs. 1 and 4). In the example shown in Figure 4 the appearance of the giant-cell remnant suggests that the nuclei of the giant cell may have undergone regression to fibrocytic nuclei, although invasion of the giant cell by fibroblasts may have taken place. The occurrence of such inflammatory reaction or fibrosis is sufficient proof that artefacts may be excluded in at least two of these cases.

In the course of these observations it was noticed that there was not infrequently some bulging of vessel walls in areas adjacent to osteoclasts. Sometimes, as in Figure 8, osteoclasts were projecting into the blood vessels although they could not be described as lying free within the vessels. In one instance there appeared to be swelling and loss of definition of the endothelial lining of the capillary wall in relation to an osteoclast which was lying outside the capillary, but which was seemingly bulging the wall of the capillary inwards (Fig. 9).

VOL. 39 B, NO. 2, MAY 1957 
Appearances such as these suggested the possibility that osteoclasts might be capable of invading capillary blood vessels by an active process which presumably would involve the lysis or enzymatic destruction of the capillary walls. A pathway of escape into the vessels

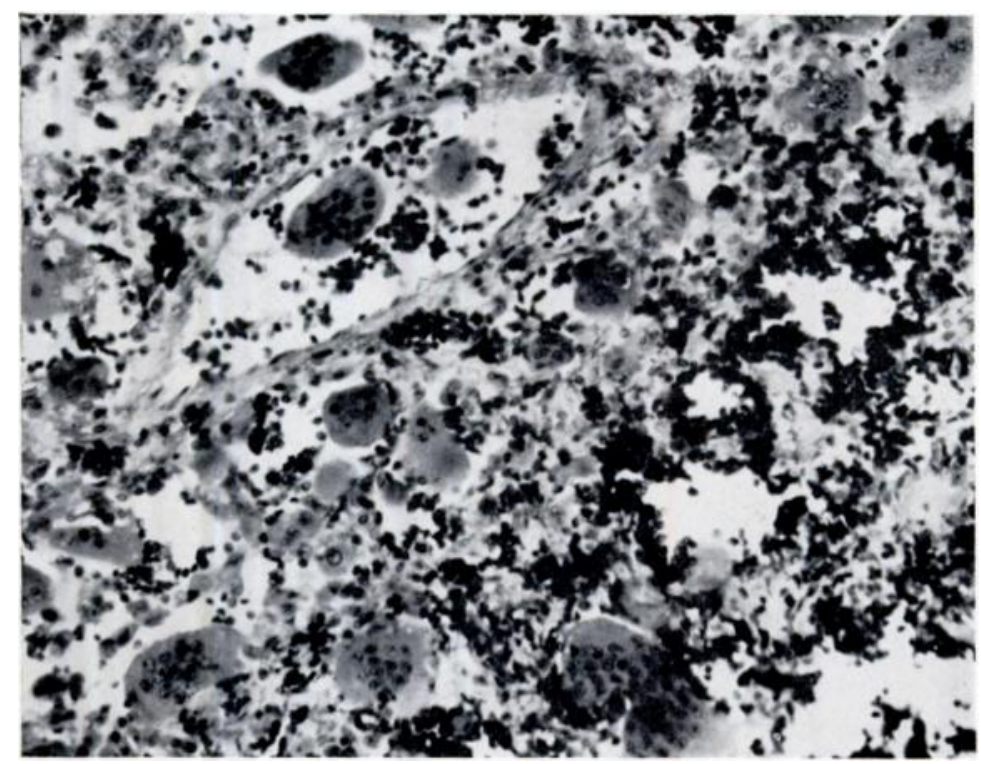

Fig. 6

Case 8-Two osteoclasts lying inside a blood vessel within the tumour. The tumour is extremely vascular and shows a considerable amount of stromal haemorrhage. (H. and E., $\times 210$.)

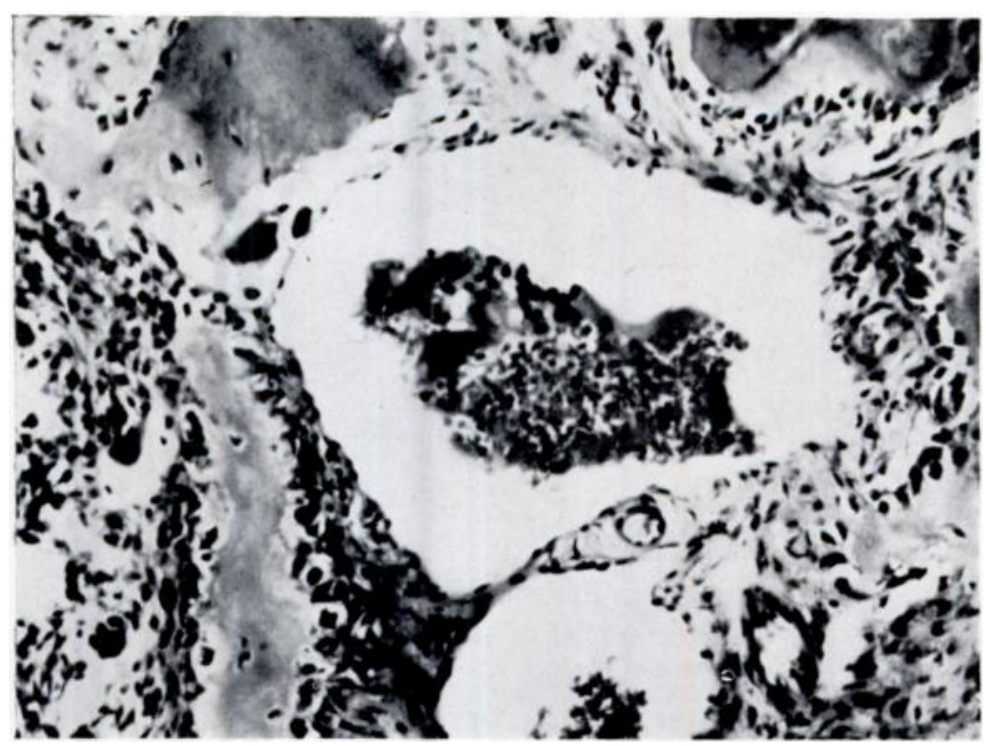

Fig. 7

Case 9-Several osteoclasts situated within a thin-walled blood sinus at the periphery of the tumour. There is reactive new bone formation in this area. (H. and E., $\times 210$.)

would thus be opened for the osteoclasts. Some evidence in support of this theory was obtained from the study of reticulin preparations of the tumours in this series.

Figure 10 shows an osteoclast lying just outside the wall of a capillary. There appears 
to be some thinning of the reticulin of the capillary wall in this region, and there is possibly slight protrusion of the cytoplasm of the osteoclast into the lumen of the vessel. A similar relationship between an osteoclast and a blood vessel is shown in Figure 11. In this case

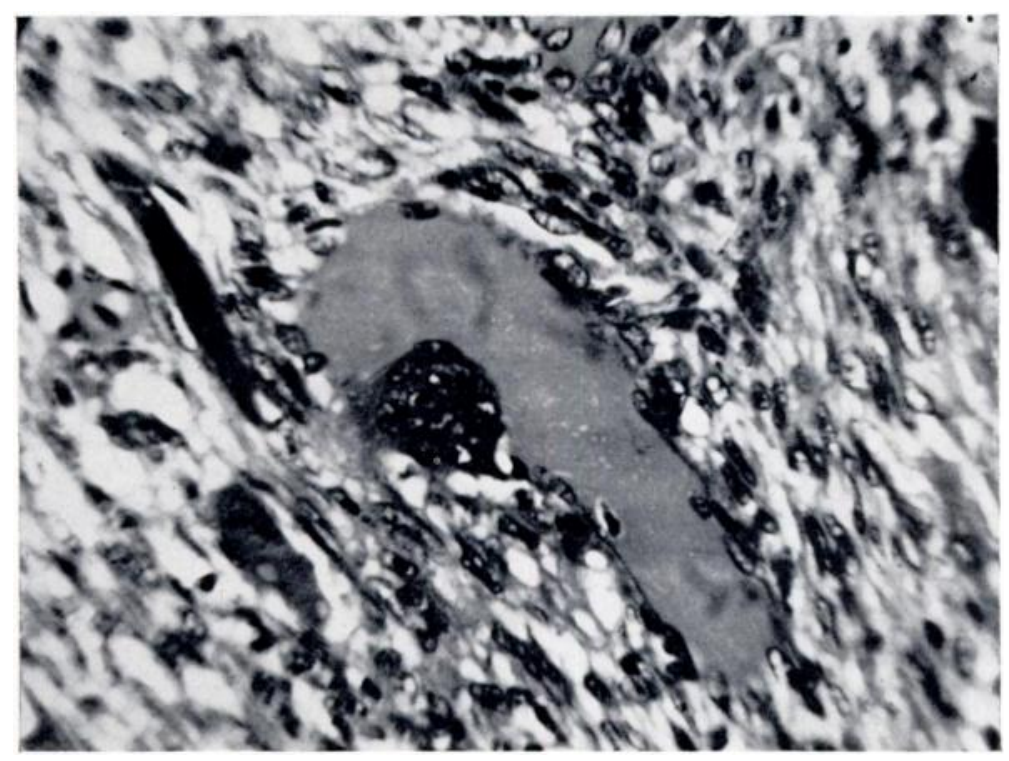

FiG. 8

Case 5-An osteoclast protruding into the lumen of a blood vessel situated within the tumour. (H. and $\mathrm{E}$., $\times 340$.)

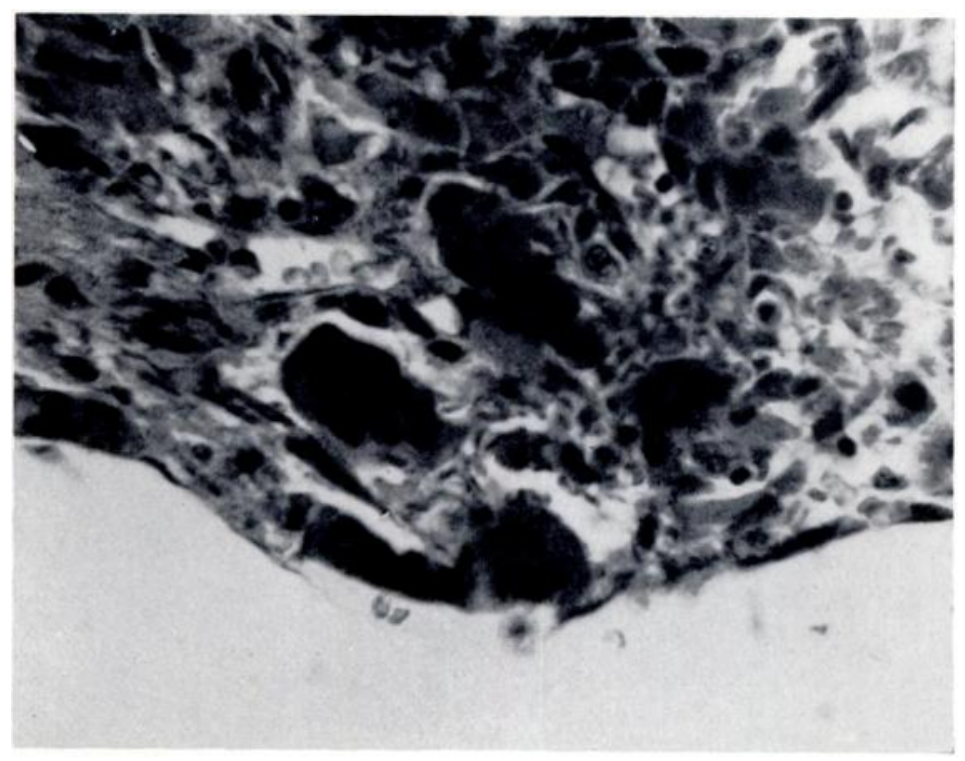

Fig. 9

Case 6-An osteoclast is shown to be lying immediately adjacent to the wall of a capillary blood vessel. The endothelial lining of the vessel is indistinct and possibly swollen where it is in contact with the osteoclast. (H. and E., $\times 340$.)

the process of weakening of the vessel wall appears to have been carried a stage further. Along the length of capillary wall which is in contact with the osteoclast, nearly all the reticulin of the capillary wall has disintegrated, leaving only a few shreds of reticulin adherent 
to the osteoclast along the line which presumably marks the former course of the blood vessel wall. Figure 8 may demonstrate a later stage in the same process.

If such a process does in fact take place, then some local action of osteoclasts upon

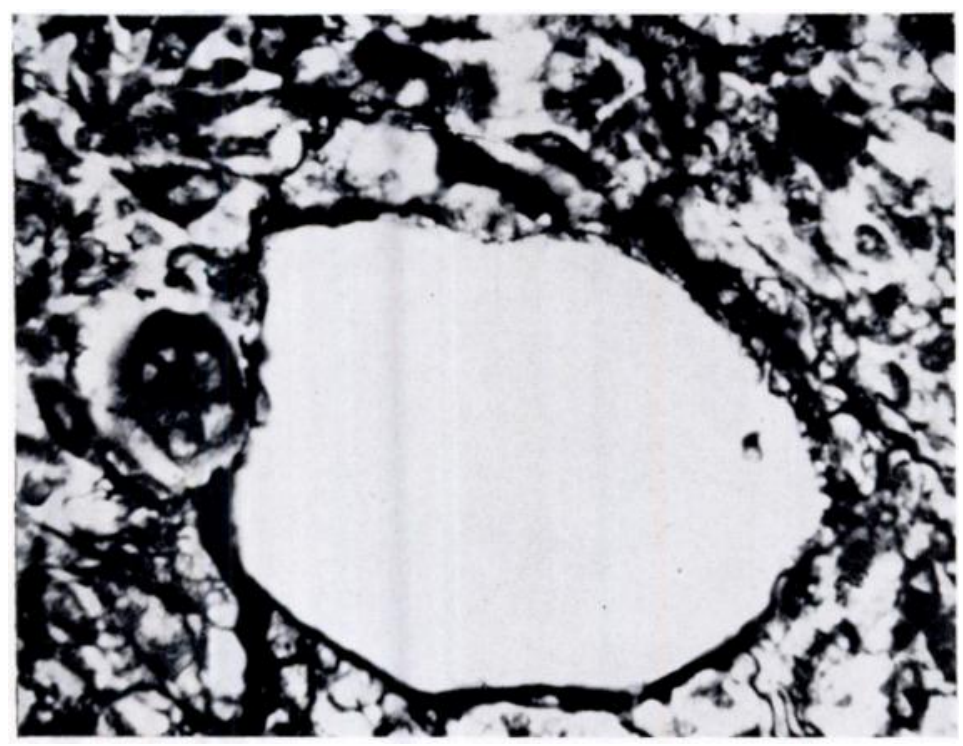

FiG. 10

Case 6-An osteoclast is shown lying close to the wall of a capillary blood vessel. There is apparent weakening of the reticulin of the capillary wall, with slight protrusion of the cytoplasm of the giant cell into the vascular lumen at one point. (Reticulin impregnation, 600.)

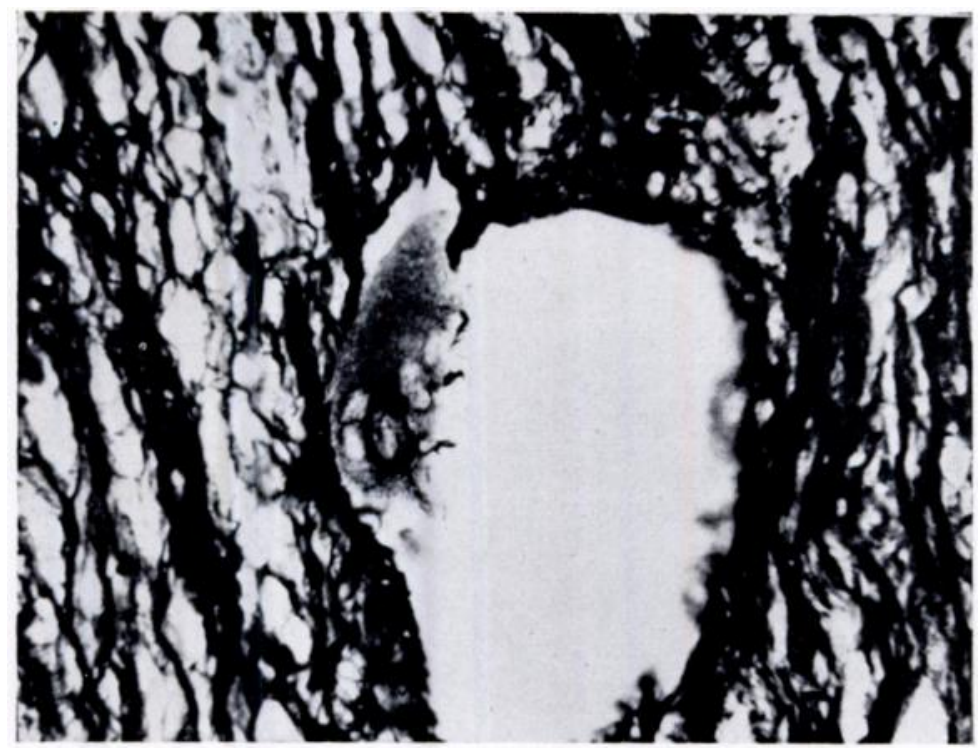

Fig. 11

Case 6-An osteoclast is lying alongside a capillary blood vessel. The wall of the capillary has been interrupted immediately opposite the osteoclast, to which a few shreds of reticulin are still adherent. (Reticulin impregnation, $\times 500$.)

the general reticulin framework of the tumours would clearly be expected to occur. A study of the reticulin pattern of the stroma of osteoclastomas shows that, in areas where reticulin fibres are running predominantly in one plane, interruption of these fibres appears to take 
place in close proximity to osteoclasts. Instead of the reticulin fibres running to either side of the obstructing cell, there appears to be some breaking of the fibres and possibly some fraying of the broken ends (Fig. 12). The impression is formed that there is some local destruction of reticulin.

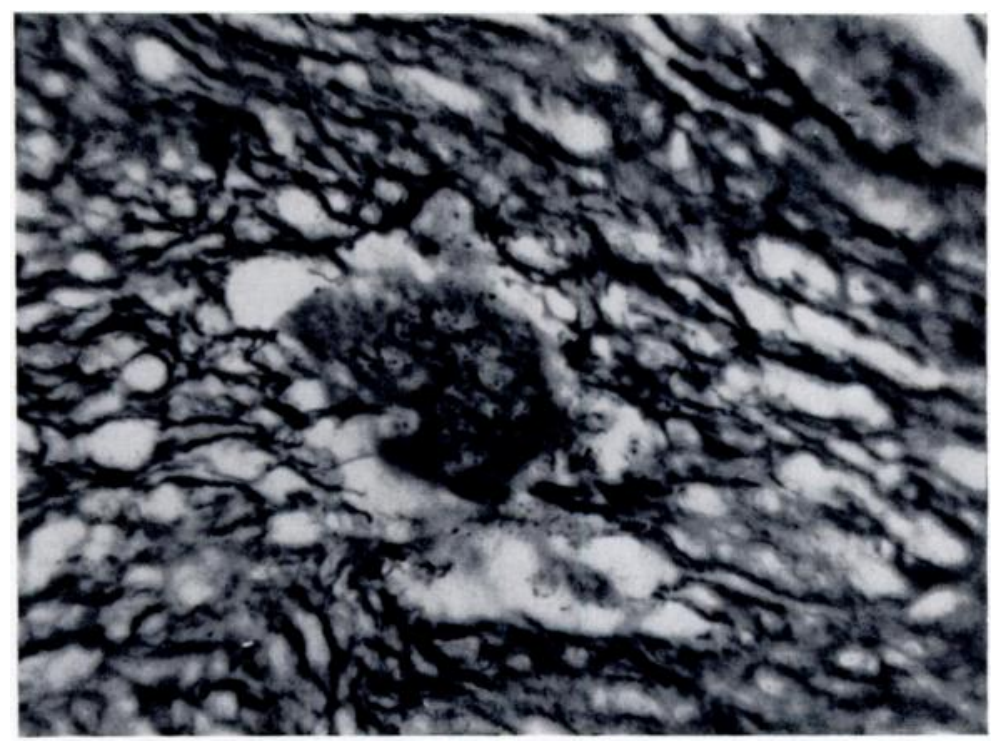

Fig. 12

Case 5-An osteoclast lying in a part of the tumour rich in reticulin fibres These are running predominantly in a more or less horizontal plane, and show apparent interruption in the immediate vicinity of the osteoclast. (Reticulin impregnation, 470.)

\section{DISCUSSION}

On the basis of these observations it can be stated that osteoclasts may be found with some frequency in the blood vessels traversing or immediately surrounding osteoclastomas. Their presence in these vessels does not appear to be in any way dependent upon the trauma of operation, because giant cells that had undergone considerable degrees of organisation or obliteration were found in Case 1, indicating that the process of vascular invasion had been taking place for a considerable time.

There does not appear to have been any clear description of this phenomenon in the past, although references to osteoclasts situated in, or lining, "blood spaces" are not uncommon in the literature of osteoclastomas.

Osteoclasts have not been described in the blood vessels or in the blood stream of man in conditions other than osteoclastoma, or in the normal individual. Arey (1920), however, while studying the embryos of pigs, observed and illustrated osteoclasts in blood vessels of the bone marrow. He wrote: "That such gain admittance and do not arise in situ from the endothelium is supported by their usual retrograde appearance; vacuolisation, granulation and loss of stainability of the cytoplasm, and pyknosis of the nuclei occur . . . the condition appears to indicate a method of final removal. This admission into embryonic vessels does not in itself prove or imply an amoeboid activity by the osteoclast."

Arey did not discuss the methods by which these cells might have gained admission to the blood stream. In theory there are a number of different ways by which osteoclasts might be enabled to enter blood vessels. 1) By the intravascular formation of osteoclasts as a result of the fusion of vascular endothelial cells. 2) By the following mechanism, which would require for its operation: $a$ ) that osteoclasts are formed by fusion of the stromal cells of 
osteoclastomas; $b$ ) that the stromal cells of osteoclastomas are derived from vascular endothelial tissues or from cells with such potentialities; $c$ ) that the structure of osteoclastomas is truly sinusoidal. If all these propositions were correct, then it might be reasonable to expect that osteoclasts would find their way into the blood stream occasionally. 3) By the diapedesis of osteoclasts through intact capillary walls. 4) By the accidental escape of osteoclasts through damaged or ruptured vessel walls. 5) By the mechanism already suggested-lysis of the vascular walls, presumably as a result of enzyme activity by the adjacent osteoclasts, with the consequent escape of osteoclasts through the damaged capillary walls.

These propositions will be considered in turn.

1. It was widely held at one time that osteoclasts were derived from vascular endothelium by fusion of the endothelial cells. This view was put forward at a time when the distinction between giant cells of osteoclastic type and those of megakaryocytic type had not been established. The evidence for this origin of osteoclasts is thus rather obscure, and no convincing evidence has since been put forward in support of this theory. It may therefore be discarded, along with the theory that vacuoles in osteoclasts represent the early stages in development of vascular channels.

2. Although it is now generally agreed that tumour osteoclasts are formed by the fusion of the stromal cells of osteoclastomas, there is still no agreement about the origin of the stromal cells. Willis (1953) mentioned fibroblasts, vascular endothelium or osteoblasts as possible sources for these cells. Even if the stromal cells and osteoclasts were derived from vasoformative tissues, and there is no evidence that they are, it would still be necessary to postulate a sinusoidal structure in these tumours to explain the entry of osteoclasts into the circulation. On the contrary, although these tumours are often very vascular, vessel walls can usually be identified, and the blood which is found in the stroma is present there in all probability as a result of haemorrhage.

3. The osteoclast is not known to be capable of amoeboid movement, and it is unlikely to be capable of diapedesis. Furthermore, it is an extremely large cell, especially in the pathological forms found in osteoclastomas. For this reason alone it would almost certainly be incapable of passing through the interstices of an undamaged capillary wall.

4. It is possible that osteoclasts may gain admission to the circulation as a result of damage to capillary walls which, in these tumours, are often very thin. Although the osteoclast is a large cell, certain conditions of trauma might allow it to enter the blood vessels. Even larger fragments of bone marrow may be found in the lungs after fractures and convulsions (Tierney 1952), and amniotic emboli are often of considerable size (Steiner and Lushbau gh 1941), although in the case of the latter there are special factors of muscular pressure and vascular structure to be taken into consideration.

One cell that is comparable in size with the osteoclast is the megakaryocyte. This cell has been found in the lungs in as many as 56 per cent of patients who died suddenly from various causes, and up to 100 per cent of patients with acute bacterial encarditis showed megakaryocytes in the pulmonary capillaries (Seebach and Kernohan 1952). It is not surprising, however, that megakaryocytes should enter the circulation, together with other immature haemopoietic cells, in conditions of acute physiological stress or even under more normal conditions.

Other benign conditions in which pulmonary intravascular deposits may be found are normal pregnancy and invasive hydatidiform mole. The presence of chorionic tissue in the circulation may be due primarily to the invasive powers of this tissue rather than to traumatic factors.

Vascular invasion is not a feature of other benign tumours, but it is possible that the relatively delicate vascular structure of osteoclastomas may predispose to the entry of osteoclasts into the circulation as a result of trauma. This possibility cannot be excluded from consideration. 
5. The observations that have been described above suggest that one mechanism by which osteoclasts enter the blood stream entails an active lysis of the vessel walls by osteoclasts. This process could be brought about by enzyme activity on the part of the osteoclasts.

Although the evidence that has been put forward in support of this possibility might seem slender, it must be remembered that there is no general agreement on the way in which normal osteoclasts assist in the resorption of bone, in spite of a considerable amount of observation and experiment which has been made in this field.

Some workers have maintained that bone destruction is the result of an osteolytic process. and that the osteoclasts serve a phagocytic purpose. This theory has been upheld by several authors, including Leriche and Policard (1928).

Others regard the osteoclast as the prime mover in the process of absorption, but while some (Jaffe et al. 1940) regarded it as a phagocytic cell in this connection, Willis (1953) denied that the osteoclast was a skeletal phagocyte.

It is thought that, whatever the exact mechanism of bone resorption may be, the collagenous matrix of bone, the ground substance and the bone salts that lie upon the matrix are all removed simultaneously in the process. It has recently been claimed that a limited process of halisteresis takes place and that the ends of collagen fibrils may be seen protruding from the surface of the bone that is undergoing resorption (Ham and Gordon 1952).

Kroon (1954) considered that osteoclasts were actively concerned in the process of bone resorption and claimed to have shown that the striated borders of osteoclasts (Kölliker's brush borders) were formed by the penetration of protoplasmic projections from the osteoclast into the bone substance; the bone substance trapped in the border was broken down and liquefied in vacuoles, which increased in number during the process.

It is perhaps also of significance that Kroon described the way in which argyrophil (reticulin) fibrils of the extracellular structure of the bone might be seen protruding regularly like teeth from the bone substance into the striated border. These fibrils he described as being suddenly broken down in the border of the osteoclast and disintegrating into black granules.

If the action of osteoclasts in the resorption of bone is accepted as a positive process, probably requiring some enzyme activity on the part of the cell, there is no great difficulty in visualising a process of slow absorption of capillary walls adjacent to the osteoclasts, with subsequent escape of the osteoclasts through the gaps thus created. The action of the osteoclasts would probably be confined to an area within a very short distance from the cell.

The formation of large holes in the walls of blood vessels would perhaps help to explain, in part at any rate, the areas of haemorrhage that are not infrequently found in the stroma of osteoclastomas.

All three histological grades of malignancy were represented among the cases in which intravascular osteoclasts were found. Of the two patients with tumours of Grade 1, one has lived for just over a year with no sign of tumour recurrence after excision and local radiotherapy. The other was treated by amputation thirteen years ago, and the patient has recently written to say that she is in excellent health.

There were two tumours in Grade 2 in which intravascular osteoclasts were found. One of the patients was well twelve years after her leg had been amputated; the other was treated by curettage and discharged from hospital fifteen months ago. There is no recent information about his progress.

The fifth tumour was placed in Grade 3. This patient had a leg amputated six months ago and so far has remained in good health.

Two tumours, in which there was protrusion of osteoclasts into blood vessels, without evidence of complete vascular invasion, were placed in Grade 1. One patient was well twenty months after the local excision of the tumour, the other has remained well for twelve years after amputation of a leg.

vol. 39 B, NO. 2, MAY 1957

$\mathbf{M}_{(8)}$ 
From these facts it seems probable that the presence of osteoclasts in the blood stream is not related to the grade of malignancy of the tumour. It must also be assumed that in at least some of these cases there was more widespread dissemination of osteoclasts than the sections indicated, without serious consequences to the patients.

The presence or absence of intravascular osteoclasts in an osteoclastoma should not, therefore, be taken into account in assessing the histological grade of such a tumour. The cellular morphology of the stroma, the degree of pleomorphism, mitotic activity, and the other features stressed by Jaffe et al. (1940), are of more importance.

The osteoclastoma may, however, be placed alongside the invasive hydatidiform mole as an example of a benign tumour which is capable of vascular invasion without the subsequent development of metastatic deposits. The suggested method of entry of osteoclasts seems unlikely to bear any relationship to the methods employed by the cells of hydatidiform mole or by the cells of malignant tumours, except in so far as enzymes may play a part in some or all of these processes.

It should be pointed out, however, that emboli of malignant tissue from other types of tumours may be found in the pulmonary blood vessels without their having given rise to metastatic deposits.

Saphir (1947) has confirmed the earlier claims of Iwasaki (1915) that tumour emboli may be made innocuous by a process of organisation, and suggests that organisation is initiated by the formation of hyaline thrombi around the emboli. The eventual intimal thickening closely resembles pulmonary arteriosclerosis.

The fate of these intravascular osteoclasts is uncertain. It appears, from the material obtained in Case 1, that some of the cells become impacted in the smaller blood vessels and are eventually incorporated into the vessel walls by a process of fibrous organisation from without. The possibility also exists that the osteoclastic nuclei retain the power of reverting to fibrocytic nuclei.

It is presumed that other osteoclasts are carried away in the general circulation and are filtered off in the capillary bed of the lungs, or that, if they succeed in passing through the lungs, they meet a similar fate elsewhere.

Only if they are derived from a malignant tumour will the osteoclasts, or the isolated stromal cells which must occasionally accompany them, possess the requisite powers of independent proliferation to form secondary deposits of tumour tissue. Even then, many of the cell emboli may be rendered harmless by the processes described above. It is not known whether any increase in malignant potentiality in the tumour is accompanied by an increased or a decreased tendency for osteoclasts to invade blood vessels.

\section{SUMMARY}

1. In five out of eleven cases of osteoclastoma it was found that osteoclasts were present inside clearly defined blood vessels either within the tumours or in the tissues immediately surrounding the tumours. In two further cases it was found that osteoclasts protruded into the vessels although they were not lying free within the vessels.

2. The possible modes of entry of these cells into the blood stream are discussed. Although accidental dissemination of osteoclasts into damaged blood vessels could not be excluded, it was felt that the process was equally likely to be related to some inherent property of the osteoclasts. From further observations it is suggested that osteoclasts are capable of local destruction of the connective tissues of the vessel walls, probably by enzyme action. Such an action might be analogous to the processes by which, in the opinion of many, osteoclasts bring about the resorption of bone.

3. There did not seem to be any relationship between the finding of intravascular osteoclasts and the malignancy of the tumour, assessing the latter either on histological or clinical grounds. 
The finding of intravascular osteoclasts does not therefore appear to be of any prognostic significance.

I am grateful to physicians and surgeons of the Nuffield Orthopaedic Centre (formerly the Wingfield-Morris Orthopaedic Hospital) and the United Oxford Hospitals for permission to include details of patients who have been under their care. I wish to thank Dr A. H. T. Robb-Smith for much helpful advice in the writing of this paper, and Mr A. Mann and Mr M. Morris for assistance with the photography.

\section{REFERENCES}

Arey, L. B. (1920): The Origin, Growth and Fate of Osteoclasts and their Relation to Bone Resorption. American Journal of Anatomy, 26, 315.

HAM, A. W., and Gordon, S. D. (1952): Nature of the So-called Striated Borders of Osteoclasts. Anatomical Record, 112, 449.

Harvey, W. F., Dawson, E. K., and InNes, J. R. M. (1940): Debatable Tumours in Human and Animal Pathology. Edinburgh: Oliver \& Boyd.

IWASAKI, T. (1915): Histological and Experimental Observations on the Destruction of Tumour Cells in the Blood Vessels. Journal of Pathology and Bacteriology, 20, 85.

Jaffe, H. L., Lichtenstein, L., and PoRtis, R. B. (1940): Giant Cell Tumor of Bone. Archives of Pathology, 30, 993.

KroON, D. B. (1954): The Bone-destroying Function of the Osteoclasts (Koelliker's “ Brush Border ”). Acta Anatomica, 21, 1.

Leriche, R., and Policard, A. (1928): The Normal and Pathological Physiology of Bone. Translated by S. Moore and A. Key. London: Henry Kimpton.

SAPHIR, O. (1947): The Fate of Carcinoma Emboli in the Lung. American Journal of Pathology, 23, 245.

Seebach, L. M., and Kernohan, J. W. (1952): Megakaryocytes in the Pulmonary Capillaries. American Journal of Clinical Pathology, 22, 646.

Steiner, P. E., and Lushbaugh, C. C. (1941): Maternal Pulmonary Embolism by Amniotic Fluid. Journal of the American Medical Association, 117, 1,245.

TieRNeY, R. B. H. (1952): Bone-marrow Embolism. Journal of Clinical Pathology, 5, 63.

Willis, R. A. (1953): Pathology of Tumours. Second edition. London: Butterworth \& Co. Ltd. 